\section{Commentary: The prognostic value of Kirsten rat sarcoma viral oncogene mutation for non-small cell lung cancer: One size does not always fit all}

\author{
David B. Nelson, MD, MSc, ${ }^{\mathrm{a}}$ and \\ Mara B. Antonoff, MD, FACS ${ }^{b}$
}

Kirsten rat sarcoma viral oncogene (KRAS) among the most common oncogenic driver mutations in non-small cell lung cancer (NSCLC). ${ }^{1}$ RAS is activated by binding to guanosine triphosphate (GTP), which subsequently activates several downstream pathways, including RAF, PI3Ks, RALGDS, and phospholipase C. ${ }^{2}$ Although there are several known KRAS mutations, the most common KRAS mutations lead to impaired GTPase activity and permanent activation of RAS signaling. Unfortunately, despite numerous efforts, there have been no effective targeted therapies for KRAS that have been developed to date.

Among those who harbor stage IV NSCLC, KRAS mutation status has been shown to be associated with poor prognosis, as demonstrated in a notable study of 1036 patients by Riely and colleagues (hazard ratio, $1.21 ; P=.048) .{ }^{3} \mathrm{How}-$ ever, a secondary evaluation of the Lung Adjuvant Cisplatin Evaluation pooled analysis, which included 4 randomized control trials of adjuvant chemotherapy for NSCLC, failed to confirm the prognostic value of KRAS. ${ }^{4}$ These disparate findings had previously led some investigators to conclude that KRAS may be an important prognostic feature among those with stage IV NSCLC, yet without relevance for those with resectable NSCLC. ${ }^{2}$

\footnotetext{
From the ${ }^{\mathrm{a}}$ Department of Surgery, Loma Linda University Health, Loma Linda, Calif; ${ }^{\mathrm{b}}$ Department of Thoracic and Cardiovascular Surgery, University of Texas MD Anderson Cancer Center, Houston, Tex.

Disclosures: The authors reported no conflicts of interest.

The Journal policy requires editors and reviewers to disclose conflicts of interest and to decline handling or reviewing manuscripts for which they may have a conflict of interest. The editors and reviewers of this article have no conflicts of interest.

Received for publication June 15, 2020; revisions received June 15, 2020; accepted for publication June 15, 2020; available ahead of print July 5, 2020.

Address for reprints: Mara B. Antonoff, MD, FACS, Department of Thoracic and Cardiovascular Surgery, University of Texas MD Anderson Cancer Center, 1400 Pressler St, Unit 1489, Houston, TX 77030 (E-mail: mbantonoff@mdanderson.org).

J Thorac Cardiovasc Surg 2022;163:e91-2 $0022-5223 / \$ 36.00$

Copyright (c) 2020 Published by Elsevier Inc. on behalf of The American Association for Thoracic Surgery

https://doi.org/10.1016/j.jtcvs.2020.06.081
}

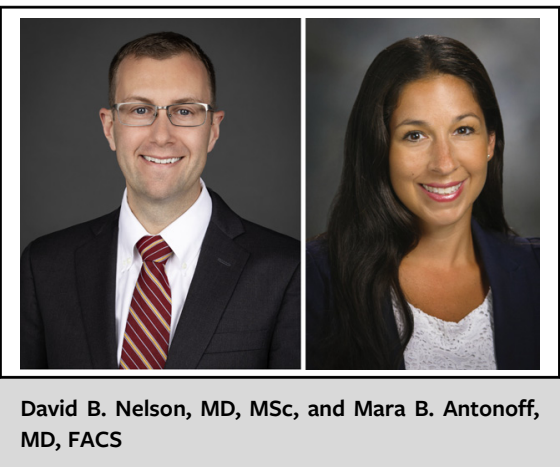

CENTRAL MESSAGE

KRAS mutation status was an independent prognostic factor for early-stage lung adenocarcinoma and for part-solid tumors, but not for stage II or III or pure-solid tumors.

In an important study by Chen and colleagues, ${ }^{5}$ KRAS mutation status was discovered to be associated with a marked decrease in recurrence-free survival among patients with stage I NSCLC (hazard ratio, 2.05; $P=.01$ ), as well as those with part-solid lung tumors. In a similar vein to the report by the Lung Adjuvant Cisplatin Evaluation Collaborative Group, ${ }^{4}$ the authors were unable to discover an association of KRAS with survival among those with stage II or III lung adenocarcinoma. This caveat suggests that, among those with resected NSCLC, KRAS status may be a key prognostic feature for early-stage lung adenocarcinoma, with its significance diminished as disease progresses to more advanced stages. Perhaps more importantly, these findings remind us of the importance of driver mutational status among early-stage lung cancer, in addition to metastatic cancer. The authors should be commended for this work that further prognosticates KRAS mutation status among those with resectable NSCLC, which lays the foundation for further research to outline the pathogenesis of the KRAS driver mutation.

\section{References}

1. D'Angelo SP, Park B, Azzoli CG, Kris MG, Rusch V, Ladanyi M, et al. Reflex testing of resected stage I through III lung adenocarcinomas for EGFR and KRAS mutation: report on initial experience and clinical utility at a single center. J Thorac Cardiovasc Surg. 2011;141:476-80.

2. Wood K, Hensing T, Malik R, Salgia R. Prognostic and predictive value in KRAS in non-small-cell lung cancer: a review. JAMA Oncol. 2016;2:805-12. 
3. Johnson ML, Sima CS, Chaft J, Paik PK, Pao W, Kris MG, et al. Association of KRAS and EGFR mutations with survival in patients with advanced lung adenocarcinomas. Cancer. 2013;119:356-62.

4. Shepherd FA, Domerg C, Hainaut P, Jänne PA, Pignon JP, Graziano S, et al Pooled analysis of the prognostic and predictive effects of KRAS mutation status and KRAS mutation subtype in early-stage resected non-small-cell lung cancer in four trials of adjuvant chemotherapy. J Clin Oncol. 2013; 31:2173-81.

5. Ma Z, Zhang Y, Deng C, Fu F, Deng L, Li Y, et al. The prognostic value of Kirsten rat sarcoma viral oncogene homolog mutations in resected lung adenocarcinoma differs according to clinical features. J Thorac Cardiovasc Surg. 2022; 163:e73-85. 